\title{
Molecular Parallels between Neural and Vascular Development
}

\author{
Anne Eichmann ${ }^{1,2}$ and Jean-Léon Thomas ${ }^{3,4,5,6}$ \\ ${ }^{1}$ Center for Interdisciplinary Research in Biology, CNRS/UMR 7241-INSERM U1050, Collège de France, 75005 \\ Paris, France \\ ${ }^{2}$ Cardiovascular Research Center, Yale University School of Medicine, New Haven, Connecticut 06510-3221 \\ ${ }^{3}$ University Pierre et Marie Curie-Paris 6, Centre de Recherche de I'Institut du Cerveau et de la Moelle Epinière, \\ UMR S975, Paris 75651, France \\ ${ }^{4}$ INSERM, U975, Paris 75651, France \\ ${ }^{5}$ CNRS, UMR 7225, Paris 75651, France \\ ${ }^{6}$ Department of Neurology, Yale University School of Medicine, New Haven, Connecticut 06511 \\ Correspondence: anne.eichmann@yale.edu
}

The human central nervous system (CNS) features a network of $\sim 400$ miles of blood vessels that receives $>20 \%$ of the body's cardiac output and uses most of its blood glucose. Many human diseases, including stroke, retinopathy, and cancer, are associated with the biology of CNS blood vessels. These vessels originate from extrinsic cell populations, including endothelial cells and pericytes that colonize the CNS and interact with glia and neurons to establish the blood-brain barrier and control cerebrovascular exchanges. Neurovascular interactions also play important roles in adult neurogenic niches, which harbor a unique population of neural stem cells that are intimately associated with blood vessels. We here review the cellular and molecular mechanisms required to establish the CNS vascular network, with a special focus on neurovascular interactions and the functions of vascular endothelial growth factors.

\begin{abstract}
A natomical parallels between the nervous Aand the vascular systems are readily apparent in peripheral body tissues, where blood vessels and nerves ramify throughout nearly all domains of the body and are usually aligned. Alignment of nerves and blood vessels allows the establishment of a physical relationship between them because larger nerves are vascularized by vasa nervorum to ensure their oxygen and nutriment supply, whereas arteries are
\end{abstract}

innervated by autonomic nerve fibers that control vascular tone. To orchestrate the formation of their highly branched, exquisitely wired networks, nerves and blood vessels have developed shared cellular and molecular principles (Larrivée et al. 2009; Tam and Watts 2010).

At the cellular level, axons of developing neurons and capillaries use specialized motile structures to ensure their directional guidance. In axons, a growth cone is situated at the axon

Editors: Michael Klagsbrun and Patricia D'Amore

Additional Perspectives on Angiogenesis available at www.perspectivesinmedicine.org

Copyright (C) 2013 Cold Spring Harbor Laboratory Press; all rights reserved; doi: 10.1101/cshperspect.a006551

Cite this article as Cold Spring Harb Perspect Med 2013;3:a006551 
extremity and ensures axon guidance toward its distant target (Tessier-Lavigne and Goodman 1996). In blood vessels, specialized motile endothelial cells (ECs) situated at the capillary tips ensure capillary guidance during sprouting angiogenesis (Gerhardt et al. 2003). Sprouting angiogenesis is the common form of neovessel formation into previously avascular tissues such as the developing brain and postnatal retina, and tumor neovascularization also proceeds by sprouting angiogenesis. For sprouting to proceed efficiently, capillaries have to designate one EC as the motile capillary "leader," with the other capillary cells termed "stalk cells" trailing behind. Whereas tip cells guide capillary outgrowth, stalk cells form the capillary lumen, allowing blood flow and oxygen and nutriment transport (Phng and Gerhardt 2009).

Molecularly, common signaling molecules guide vascular and axonal outgrowth. Growth cones project numerous filopodia that actively extend and retract in response to four families of extracellular guidance cues: ephrins, semaphorins, netrins, and slits. Guidance cues can be divided into attractive or repulsive signals that tell the growth cone where and where not to migrate, respectively. These cues can also be divided into those that are cell-membranebound, and thus act on nearby axons, and those that are secreted and form gradients that influence the trajectories of extending axons. Axonal growth cones and tip cells express receptors for axon guidance molecules, including Neuropilin receptors (Nrps), Eph family receptor tyrosine kinases, PlexinD1, Robo4, and UNC5B (Larrivée et al. 2009). Among those, Nrps and Eph receptors show shared expression in both the vascular and the nervous systems, whereas Robo4, UNC5B, and PlexinD1 are predominantly expressed in the vasculature, with only a few expression sites in other tissues. Loss of function of the genes encoding these receptors leads to defects in vessel formation and in most cases to embryonic death, indicating a critical function of axon guidance receptors in vascular development. Their guidance properties and vascular expression make them attractive targets for approaches directed at inhibiting tumor angiogenesis, or conversely for guiding new vessels toward ischemic tissue areas (Klagsbrun and Eichmann 2005).

In addition to cues initially discovered for their role in axon guidance that play a role in vessel formation, an increasing body of evidence shows that vascular endothelial growth factors (VEGFs) and their high-affinity tyrosine kinase VEGF receptors also regulate development of the nervous system. Evolutionarily, the nervous system is already present in small invertebrates such as nematodes, which lack a vascular system and distribute oxygen by diffusion, but nevertheless express orthologs of tyrosine kinase VEGF receptors. Nematode VERs (vascular endothelial growth factor receptor related) are expressed by neuronal and glial cells and required for nervous system development (Popovici et al. 2002; Procko et al. 2011). In vertebrates, VEGF family members are critical regulators of angiogenesis, and agents blocking VEGF binding or signaling through its receptors are used in the clinic to block tumor angiogenesis and progression as well as retinal vasoproliferative disease (Ferrara et al. 2003; Ferrara 2010). VEGF, however, has retained important functions in the vertebrate nervous system and coordinates many aspects of neurovascular interactions (Rosenstein et al. 2010).

During embryonic development, brain and spinal cord derive from ectoderm, a tissue devoid of the capacity to generate ECs, and their growth depends on oxygen and nutriment delivery from the blood vessels that invade the brain from the surrounding mesodermal layers. Expansion of the head and forebrain in vertebrates coincided with the appearance of a pluripotent embryonic cell population called the "neural crest cells" that gives rise, among other tissues, to meninges and pericytes that invade the forebrain together with ECs (Etchevers et al. 2001). Once within the central nervous system (CNS), the vascular and nervous systems form an intricate interface composed of EC, pericytes, glia, and neurons, which are tightly coupled to control cerebrovascular exchanges (Iadecola 2004; Hawkins and Davis 2005). A major consequence of this interface is the 
establishment of the blood-brain barrier (BBB), a unit formed by ECs, pericytes, and astrocyte end feet that regulates the movement of molecules, ions, and cells between the blood and the neural tissues (Engelhardt 2003). BBB ECs are characterized by the presence of tight junctions, expression of specialized transporters and pumps, and reduced basal endocytic activity as compared with ECs found in peripheral organs. The BBB protects the brain from toxins in the blood and transports glucose, one of the primary energy sources, to the brain via the glucose transporter 1 (Glut1) (Rubin and Staddon 1999).

The adult mammalian brain retains the potential to generate new neurons throughout life. This potential is restricted to a limited number of sites, called "neurogenic niches." The neurogenic niches harbor a unique population of neural stem cells (NSCs), self-renewing cells with hallmarks of astrocytes that generate neurons and glia. Injury of brain tissue resulting from trauma, hypoxia, or neuron-glial pathologies activates neurogenesis in these niches, offering exciting novel avenues for treating neurological disorders by promoting endogenous neurogenic activity. NSCs are intimately associated with ECs within the niches, allowing constant access to circulating signaling molecules and nutrient metabolites (Shen et al. 2008; Tavazoie et al. 2008). Interestingly, VEGFs are also critically involved in neurogenesis, including NSC development.

Below we describe recent work that has identified cellular and molecular mechanisms required to establish the vascular network and $\mathrm{BBB}$ in the CNS, and then focus on the neurovascular interactions in adult neurogenesis and the role of VEGFs in neural development and brain plasticity.

\section{DEVELOPMENT AND MATURATION OF CNS VESSELS}

Invasion of the neural tube by capillaries has been investigated in detail in classic studies using India ink injection into avian embryos (Feeney and Watterson 1946). Invasion of the neural tube proceeds along a rostrocaudal gradient and follows a highly reproducible spatio-temporal sequence (Fig. 1). Vessels initially invade the neural tube on both sides of the floor plate, an important ventral patterning center that regulates laterality of neuronal development and midline axon guidance. Vessels migrate up to the mid-height of the neural tube and then form a series of lateral branches, which are highly similar between embryos of the same stage (Fig. 1).

VEGF has been implicated in the control of CNS angiogenesis. VEGF transcript levels are abundant in the ventricular neuroectoderm of embryonic and postnatal brain when ECs proliferate rapidly but are reduced in the adult when EC proliferation has ceased. The temporal and spatial expression of VEGF is consistent with the hypothesis that VEGF is synthesized and released by the ventricular neuroectoderm and may induce the ingrowth of capillaries from the perineural vascular plexus (Breier et al. 1992). Numerous studies using pharmacologic or genetic blocking of VEGF to inhibit capillary invasion of the brain indicate that VEGF is crucial for brain vascularization (Raab et al. 2004; Bautch and James 2009). VEGFR2 expressed on invading capillary EC is required for vessel ingrowth into the neural tube. Nrp1, a coreceptor for heparin-binding forms of VEGF, notably VEGF164, is also necessary for proper CNS vascularization ( $\mathrm{Gu}$ et al. 2003).

Like the brain, the postnatal retina is also initially avascular and invaded by vascular sprouts from the optic nerve, a process that occurs during the first two postnatal weeks in mice (Dorrell et al. 2007). VEGF produced by hypoxic retinal astrocytes leads to tip cell migration via VEGFR2 (Gerhardt et al. 2003). Tip cells show characteristic gene expression profiles (Del Toro et al. 2010; Strasser et al. 2010) and produce high levels of the Notch ligand Dll4, which signals to adjacent cells expressing Notch receptors to suppress tip cell formation, such that they become follower "stalk" cells, proliferating ECs that form the capillary lumen and allow blood transport and tissue oxygenation. Stalk cells down-regulate expression of VEGFR2 and VEGFR3 and increase levels of the decoy 


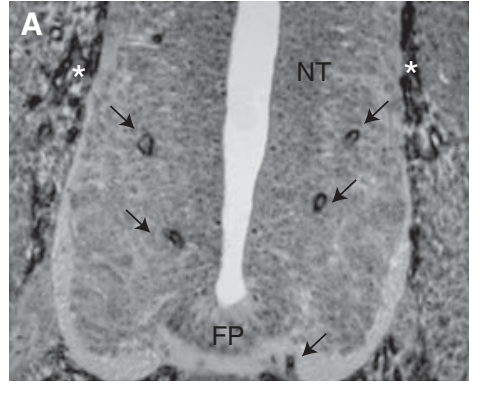

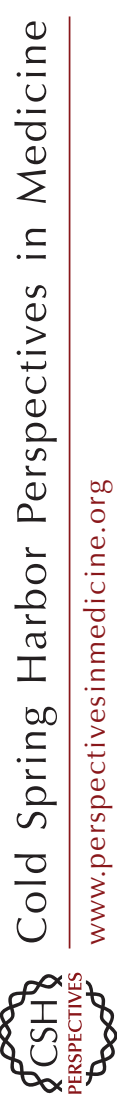

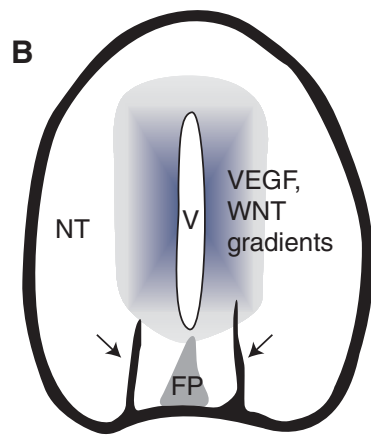

PNVP

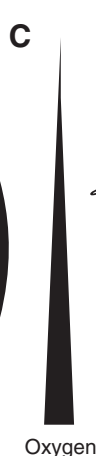

Oxygen

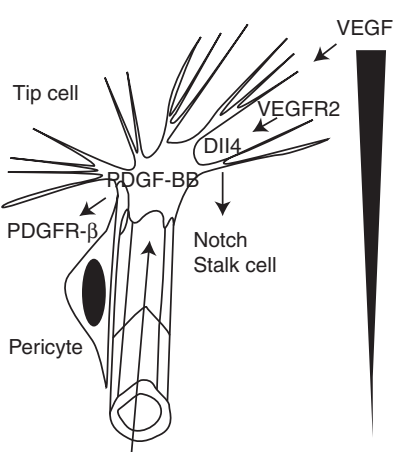

Blood flow

Figure 1. CNS vascularization. (A) Invasion of the spinal cord by ECs from the perineural vascular plexus. A quail neural tube (NT) section stained with QH1, an EC-specific monoclonal antibody. (Arrows) ECs from the $\left({ }^{*}\right)$ peri-neural vascular plexus (PNVP) invade the neural tissue on both sides of the floor plate (FP). (B) Schematic representation of EC invasion of the NT. Vessels from the PNVP invade the NT and grow toward the ventricle $(V)$, where VEGF and Wnt factors are produced. $(C)$ High magnification of the leading edge of capillaries invading the CNS. A leading tip cell extends filopodia toward hypoxic regions producing VEGF; note the opposing gradients of oxygen availability and VEGF production (triangles). Tip cells react to VEGF via VEGFR2 expressed on filopodia. Tip cell Dll4 activates Notch signaling on adjacent ECs, which differentiate into stalk cells that form a lumen allowing blood flow and tissue oxygenation. The PDGF-BB produced by tip cells promotes recruitment of pericytes expressing PDGFR- $\beta$.

receptor VEGFR1, altogether becoming less sensitive to VEGF (Hellstrom et al. 2007; Suchting et al. 2007; Tammela et al. 2008).

Quail-chick chimeras have shown that pericytes penetrate into the brain together with mesoderm-derived ECs and have diverse origins (Etchevers et al. 2001). In the forebrain, pericytes derive from the neural crest, whereas more caudally they are generated in the paraxial mesoderm. Migrating EC tip cells produce high levels of platelet-derived growth factor $B$ (PDGF-B), which signals to its receptor PDGFR- $\beta$ on pericytes to promote pericyte recruitment to ECs (Figs. 1 and 2). Mice deficient for either the ligand or the receptor show a complete lack of pericyte investment of brain vessels and die perinatally from microaneurisms and hemorrhage (Lindahl et al. 1997). PDGF-B contains positively charged stretches of amino acid residues at the carboxyl terminus, which control retention of the protein in the ECM. Genetic deletion of these residues in $P d g f r \beta^{\text {ret/ret }}$ mice led to abnormal pericyte recruitment, indicating that retention of PDGF-B in the ECM is required for pericyte apposition to ECs (Lindblom et al. 2003). Interestingly, two recent reports indicate that pericytes are also necessary for the formation and regulation of the BBB (Armulik et al. 2010; Daneman et al. 2010). ECs were shown to express tight junction molecules and the BBB-specific marker glucose transporter 1 (Glut1) as early as embryonic day 11 (E11) (Daneman et al. 2010). Contrary to the prevailing hypothesis that astrocytes induce the formation of the $\mathrm{BBB}$ postnatally, a functional $\mathrm{BBB}$ is thus present during embryogenesis, before astrocytes are generated. Newborn $P d g f r \beta^{-/-}$mice showed an increased brain vascular permeability to biotin, and the number of pericytes was inversely correlated with the permeability of the BBB in neonatal $P d g f r \beta$ hypomorph mice (Daneman et al. 2010). $P d g f r \beta^{\text {ret/ret }}$ mice also displayed an increased $\mathrm{BBB}$ permeability to water and to a range of tracers of different molecular masses, suggesting that pericytes are necessary for proper $\mathrm{BBB}$ formation and that PDGFR $\beta$ signaling in pericytes allows establishment of the BBB in the microvasculature of the CNS (Armulik et al. 2010). 

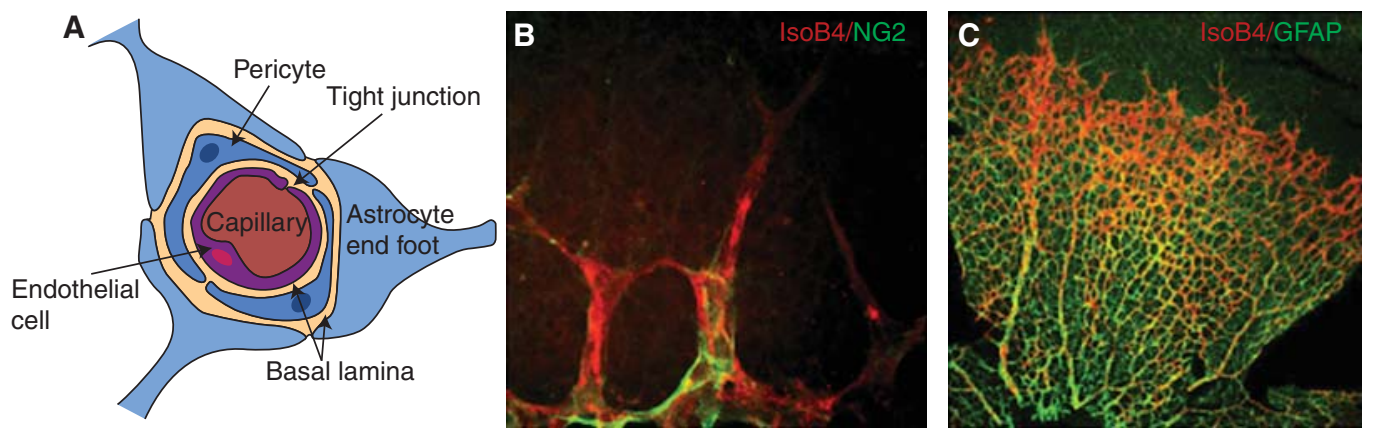

Figure 2. Maturation of CNS blood vessels. (A) In brain capillaries, ECs form the BBB through formation of tight junctions and by limiting transport through cells by highly selective trancytosis (data not shown). The functional characteristics of this vasculature require interactions and continual cross talk between ECs, pericytes, astrocytes, and neural cells (data not shown). Only the astrocyte "end foot" (the tip of the cell that is physically connected to the capillary wall) is shown. The basal lamina, layers of extracellular matrix, surrounds the cells of the capillaries. (B) Confocal image of retinal tip cells stained with IsolectinB4 (red) and a closely associated NG2-positive pericyte (green). (C) Retinal ECs (red) also closely associate with GFAP-positive astrocytes. Magnification, $40 \times(B) ; 10 \times(C)$.

\section{CNS-SPECIFIC REGULATORS OF ANGIOGENESIS IN DEVELOPMENT AND DISEASE}

In addition to VEGF, Notch, and PDGF signaling pathways, numerous other molecular mediators of angiogenesis including Angiopoietin-1 and -2 (Ang-1, Ang-2) and their receptor Tie2 and members of the transforming growth factor (TGF) $-\beta$ superfamily together orchestrate angiogenesis in the brain and elsewhere in the organism (Lee et al. 2009). Interestingly, CNSspecific regulators of angiogenesis have been recently identified. They include the Wnt/ $\beta$-catenin signaling pathways and the orphan G-protein-coupled receptor (GPCR124).

Wnts are a large family of secreted glycoproteins that signal through distinct pathways, referred to as the canonical or Wnt/ $\beta$-catenin pathway and the noncanonical Wnt/calcium and planar cell polarity (PCP) pathways (Franco et al. 2009; Dejana 2010). Wnt7a and Wnt7b ligands are produced by the neuroepithelium, coincident with vascular invasion (Stenman et al. 2008; Daneman et al. 2009). Genetic loss of function of both Wnt ligands specifically disrupted CNS, but not non-CNS angiogenesis, indicating that the Wnt signaling pathway promotes formation and CNS-specific differentiation of the brain vasculature. Vascular defects included reduction in vessel number, loss of capillary beds, the formation of hemorrhagic vascular malformations that remained adherent to the meninges, and down-regulation of the expression of the BBB-specific glucose transporter Glut-1, this latter feature indicating that Wnt signaling might control both angiogenesis and establishment of the BBB. Wnt reporter mice, which express the lac $Z$ gene under the control of Tcf promoters and synthesize lacZ in cells in which canonical Wnt/ $\beta$-catenin signaling is activated, identified activated canonical Wnt $/ \beta$-catenin signaling in CNS blood vessels and endothelial-specific $\beta$-catenin knockout mice showed disruption of CNS angiogenesis (Stenman et al. 2008; Daneman et al. 2009). In addition, $\beta$-catenin TCF-mediated canonical Wnt signaling in ECs was shown to be necessary and sufficient to induce the mature molecular and structural properties of BBB-type endothelial tight junctions and full barrier maturation in vitro and in vivo (Liebner et al. 2008).

Human ophthalmic diseases such as Norrie disease are known to result from loss-offunction mutations in genes encoding the cysteine-knot protein Norrin, the Wnt receptor Frizzled-4, and its coreceptor low-density 
lipoprotein 5 (Lrp5) (Warden et al. 2007). Several recent studies have analyzed the expression and function of Norrin in CNS angiogenesis and shown that the canonical Wnt signaling pathway was required by retinal ECs, but surprisingly, upon activation by non-Wnt ligands (Junge et al. 2009; Ye et al. 2009). Norrin produced by Muller glia cells promotes the vascularization of the developing retina by activating endothelial Frizzled-4 receptor leading to activation of $\beta$-catenin. Sox17 is up-regulated in response to Norrin-induced $\beta$-catenin signaling, and Sox17 overexpression rescues defects in capillary formation in cultured EC lacking Frizzled-4. Sox17, therefore, likely mediates the angiogenic effect induced by Norrin signaling in CNS ECs. Junge et al. (2009) found that mice carrying mutations in Tspan12, a tetraspanin family member, showed many of the defects observed in mutants lacking Norrin, Frizzled-4, or Lrp5. Tspan12 is uniquely expressed in the retinal vasculature, and compound heterozygous mice lacking one allele each of Tspan12 and Norrin or Tspan12 and Lrp5 show an increase in retinal pathology, showing a genetic interaction between Tspan12 and components of the Norrin receptor-ligand complex. Signaling defects caused by mutant forms of Norrin or Frizzled-4 are rescued by overexpression of Tspan12, indicating that Norrin and Tspan 12 may promote multimerization of the Frizzled4/Lrp5 complex and cooperate to activate $\beta$ catenin. Thus, Wnt or Norrin ligands can activate canonical $\beta$-catenin signaling during CNS angiogenesis.

The orphan G-protein-coupled receptor GPR124, previously identified as tumor endothelial marker 5, has been recently included among the specific regulators of CNS angiogenesis (Kuhnert et al. 2010; Anderson et al. 2011). Gpr124 is highly expressed in CNS endothelium and required for proper angiogenic sprouting into the developing neural tube. Following genetic deletion of Gpr124, embryos show delayed vascular penetration, formation of pathological vascular tufts within the CNS, and hemorrhage. Inducible endothelial CreERmediated deletion of GPR124 using a floxed Gpr124 allele crossed to PDGFB-iCre mice phenocopied these defects, showing the endothelial cell-autonomous function of GPR124. Interestingly, GPR124 deletion did not impair angiogenic sprouting into the embryonic diencephalon, midbrain and hindbrain, suggesting that it affects angiogenesis in selective regions of the brain. Furthermore, Tie2-Gpr124 transgenic mice overexpressing Gpr124 in ECs produced CNS-specific hyperproliferative vascular malformations. In vivo, GPR124 functioned cell-autonomously in EC to regulate sprouting, migration, and developmental expression of the Glut1, whereas in vitro, GPR124 mediated Cdc42-dependent directional migration to forebrain-derived, VEGF-independent cues. A possible link between GPR124 and canonical Wnt signaling appears unlikely, because $\beta$-catenin signaling was still present in the absence of GPR124 (Kuhnert et al. 2010). Anderson et al. (2011) showed that TGF- $\beta$ stimulates Gpr124 expression, and ablation of Gpr124 results in perturbed TGF- $\beta$ pathway activation, suggesting roles for GPR124 in modulating TGF- $\beta$ signaling. The TGF- $\beta$ pathway likely mediates cellular communication between ECs and pericytes or astrocytes, because TGF- $\beta$ inhibition results in aberrant sprouting and hemorrhage (Garcia et al. 2004; Takata et al. 2007).

\section{BLOOD VESSELS GUIDE AXON OUTGROWTH AND NEURONAL MIGRATION}

Impairment of CNS angiogenesis following mutations in the genes described above leads to reduced CNS tissue growth and viability, presumably due to the absence of oxygen and nutriment supply from blood vessels. In addition, however, vessels can also instruct nervous system development by secreting neurotrophic factors and, beyond simple feeding pipelines, serve roles that are just beginning to be unraveled.

In the peripheral nervous system, sympathetic axons grow toward their targets by following arteries, which release neurotrophic factors such as artemin and endothelin that are required for sympathetic axon outgrowth (Damon et al. 2007; Makita et al. 2008). Because 
arteries themselves are also targets for sympathetic axon innervation, it remains to be determined how sympathetic axons are directed to innervate the artery or to travel along it toward other end organs.

In the developing CNS, the vasculature is required by subsets of neural precursors to migrate toward their targets. For example, the meninges of the embryonic forebrain control the tangential migration of Cajal-Retzius (CR) cells. CR cells are a pioneer neural cell population critical for the development of the cerebral cortex. They are located in the marginal zone of the cortex, apposed to the meningeal membranes of the peri-neural vascular plexus. CR cells secrete the extracellular protein Reelin, which orchestrates the migration and laminar arrangement of the myriads of neurons that constitute the adult cerebral cortex. CR cells emerge from focal points in the embryonic telencephalon and subsequently spread tangentially for vast distances along the cortical surface until the entire cortical primordium is covered. CR cells contact the meninges, and meninges were found to be necessary and sufficient to direct CR cell migration (Borrell and Marin 2006). Interactions between CXCR4 expressed by CR cells and its ligand stromal cell-derived factor-1 (SDF-1) produced by meninges mediate this effect.

In the adult mammalian brain, olfactory neuron precursors migrate along vessels in the rostral migratory stream (RMS) (Snapyan et al. 2009). The olfactory bulb (OB) is one of the few regions in the adult brain that continues to renew its interneuronal population throughout the life span of the animal. The neuronal progenitors originate from stem cells located in the subventricular zone (SVZ), as described below, and course along the RMS - a long and intricate migratory pathway-toward the OB, where they differentiate into local interneurons. Real-time video-imaging experiments of cell migration in slices of the adult mouse forebrain showed that neuroblasts migrate close to the blood vessels with their soma and leading process (Snapyan et al. 2009). Once in the OB, a subset of these newly arrived olfactory neuron precursors follow a vasophilic migration around radial blood vessels to cross the granule cell layer toward the periphery of the OB (Bovetti et al. 2007). ECs of the RMS synthesize brain-derived neurotrophic factor (BDNF), which fosters neuronal migration via p75NTR expressed on neuroblasts (Snapyan et al. 2009).

\section{THE NEUROVASCULAR NICHE FOR NEUROGENESIS}

Adult neurogenesis relies on neural stem cells (NSCs), which have characteristics of differentiated astroglial cells and derive from the radial glia cells lining the lateral ventricles in the neonatal brain (Merkle et al. 2004; Kriegstein and Alvarez-Buylla 2009). NSCs are concentrated in a limited number of niches, including the rostral subventricular zone (SVZ) (Doetsch 2003), which renews the interneurons of the $\mathrm{OB}$, and the subgranular zone (SGZ) of the hippocampal dentate gyrus (DG) (Kuhn et al. 1996; Palmer et al. 2000), which produces new granular interneurons. In both SVZ and SGZ niches, the NSCs and actively dividing progenitors are nested around blood vessels, allowing constant access to circulating signaling molecules and nutrient metabolites (Fig. 3).

Recent studies provided high-resolution, three-dimensional (3D) descriptions of the adult SVZ, with a network of planar interconnected blood vessels that extends just beneath the ependymal layer (Shen et al. 2008; Tavazoie et al. 2008). In addition, SVZ vessels are unusually permeable: Some of them are devoid of a complete pericyte sheath, thus of a normal $\mathrm{BBB}$, and the majority of actively dividing stem/progenitor cells are closely apposed to the laminin-containing ECM surrounding ECs at these sites (Tavazoie et al. 2008). Endothelialderived factors were shown to stimulate NSC self-renewal and enhance neurogenesis in vitro (Shen et al. 2004), suggesting that the direct contact of niche stem/progenitor cells with ECs may facilitate their access to these factors. Pigment-epithelium-derived factor (PEDF) has been shown to regulate self-renewal of NSCs in the niches (Ramírez-Castillejo et al. 2006). PEDF is an anti-angiogenic factor that circulates in the plasma and CSF (Tombran-Tink 
A. Eichmann and J.-L. Thomas

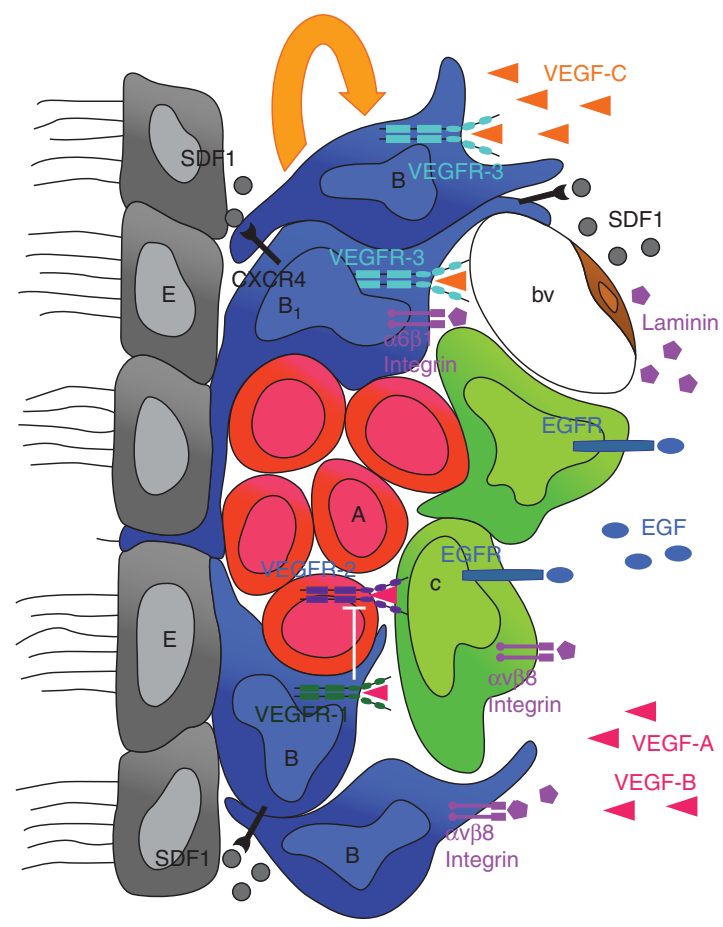

Figure 3. Interactions in the neurovascular niche. The niche is localized between the ependymal layer (E, gray) of lateral ventricles and a planar network of blood capillaries (bv, brown). It is composed of resident astroglial cells (type B, blue) including NSCs (type B1, blue), actively proliferating progenitors (type C, green), which generate neuroblasts (type A, red) migrating to the OB via the RMS. Quiescent NSCs are in subependymal position with an apical process in contact with the ventricular space, whereas actively proliferating progenitors preferentially associate with the surface of blood vessels. Both the ependyma and vessels express SDF1, which controls, through CXCR4, the homing of neural progenitors and NSCs in the SVZ and drives the expression of receptors that regulate proliferative behavior (EGFR) and cell adhesion (a6b1). Astroglial expression of the $\alpha \mathrm{v}$ subfamily of integrins, including $\alpha v \beta 8$, is critical for proper regulation of CNS angiogenesis and blood-brain barrier formation, by interaction with ECM molecules of the basement membrane, such as laminin. VEGFR family members have complementary expression pattern and function in the niche. The astroglial compartment expresses VEGFR-1 and VEGFR-3, the pool of neuroblasts expresses VEGFR-2, and ECs express VEGFR-1 and VEGFR-2. Coexpression of VEGFR-3 and EGFR in astrocytes characterizes NSCs. VEGF-C produced by SVZ astrocytes and also other cell types promotes activation of VEGFR-3-expressing cells, which increase in number following overexpression of VEGF-C. This enhances the number of type $\mathrm{C}$ cells and neuroblasts, without angiogenic effects in the niche. On the other hand, VEGF-A promotes angiogenesis and survival of neuroblasts. These effects are antagonized by astrocytes expressing VEGFR-1, which traps excess VEGF-A.

and Barnstable 2003). It is also widely distributed in the nervous system, and in the adult SVZ, both the ependymal layer and ECs produce PEDF, which induces self-renewal of cultured NSCs. PEDF likely contributes to maintain the pool of NSCs by regulating NSC-Notch signaling (Andreu-Agulló et al. 2009). The identity of the receptor that initiates PEDF signaling remains unknown, because inhibition of its only known putative receptor adipose triglyceride lipase11 did not affect PEDF actions on NSCs (Andreu-Agulló et al. 2009).

The specific homing of NSCs to vessels in the niche appears to be regulated by SDF-1, which is expressed by both SVZ vessels and the ependymal layer of ventricles. SDF-1 regulates the adherence of NSCs and rapidly dividing 
Vascular and Neural Development

progenitors to blood vessels via CXCR4, by increasing NSC expression of EGFR and integrin $\alpha 6 \beta 1$ (VLA6), a receptor for laminin, which localizes around blood vessels (Fig. 3) (Kokovay et al. 2010). NSCs express the $\alpha 6 \beta 1$ integrin, and infusion of an integrin-neutralizing antibody into the lateral ventricle of adult mice released SVZ cells from the vasculature and increased cell proliferation. A similar phenotype was observed in the embryo using blocking antibodies against $\beta 1$ integrin (Loulier et al. 2009). The $\beta 8$ integrin, which is required for the integrin-mediated activation of latent transforming growth factor- $\beta 1$ (TGF- $\beta 1$ ) and for inducing canonical TGF- $\beta$ receptor signaling (Sheppard 2004), also regulates neurovascular interactions. Deletion of the $\alpha \mathrm{v}$ or $\beta 8$ integrin genes in developing neural progenitors and astrocytes, but not ECs, leads to embryonic and neonatal blood vessel patterning defects and intracerebral hemorrhage (McCarty et al. 2005; Proctor et al. 2005), whereas homozygous $\beta 8$ deletion induces neonatal neurovascular defects including reduced cell proliferation in the SVZ and an increased number of intracerebral blood vessels with pronounced perivascular astrogliosis (Mobley et al. 2009).

Blood vessels of the "neurovascular niche" provide circulating hormones, such as prolactin or testosterone, which indirectly regulate neurogenic activity. Prolactin, which is secreted from the anterior pituitary gland, enters the SVZ via the vasculature, where it cooperates with $\mathrm{TNF} \alpha$ to increase $\mathrm{OB}$ neurogenesis during pregnancy, which is necessary for appropriate maternal olfaction (Shingo et al. 2003). In the higher vocal center (HVC) of the forebrain of adult songbirds, where neurogenesis proceeds throughout life, testosterone provides key neurogenic signals (Louissaint et al. 2002; Hartog et al. 2009). Testosterone increases VEGF and VEGFR-2 expression in neural cells and ECs, respectively, thereby stimulating angiogenesis. The expanded vasculature acts as a source of BDNF, which promotes the migration of new neurons toward the HVC. The niche vessels have therefore a dual function: to deliver the hormonal signal from the blood to the neural cells, and to secrete factors such as
BDNF that promote neurogenesis and neuroblast migration.

\section{VEGF SIGNALING IN NEURONAL PROGENITORS DURING DEVELOPMENT AND IN THE ADULT}

In some instances, VEGF directly stimulates neurogenesis, in addition to stimulating proneurogenic angiogenesis. In embryonic mouse forebrain and embryonic cortical neurons grown in vitro, VEGF-A acts as an autocrine survival factor for VEGFR-2-expressing postmitotic neurons (Ogunshola et al. 2002). In the mouse retina, embryonic as well as adult neuronal progenitor cells express VEGFR-2 (Yang and Cepko 1996). Neonatal retinal neurogenesis is developmentally regulated by VEGF, which stimulates proliferation of retinal progenitor cells and promotes production of amacrine neurons and photoreceptor cells (Yourey et al. 2000). In the avascular chicken retina, VEGFR-2-expressing progenitor cells respond to VEGF-A derived from postmitotic neurons, which increases their proliferation and decreases their differentiation into retinal ganglion cells (Hashimoto et al. 2006). In the adult rat brain, VEGFR-2 is expressed by neuronal progenitors in the lateral SVZ, and intracerebral administration of VEGF-A stimulates both neurogenesis and angiogenesis in the SVZ and in the hippocampus (Jin et al. 2000). VEGFR-1 can modulate the response of neuronal progenitors to VEGF-A, as shown in the adult mouse SVZ and RMS (Wittko et al. 2009). Specific deletion of the VEGFR-1 kinase domain increased proliferation and reduced differentiation of SVZ progenitors, associated with alterations of their migration along the RMS. The proposed model is that niche astrocytes expressing VEGFR-1 compete with VEGFR-2-expressing neuronal progenitor cells for VEGF-A binding, which antagonizes VEGFR-2 activation in these cells (Fig. 3). In the neonatal cerebellum, the granule cells migrate radially from the external granular layer (EGL), which expresses low levels of VEGF-A toward the Purkinje cell layer (PCL), where high levels of matrix-bound VEGF-A isoforms 
are deposited around the dendrites of Purkinje cells. Granule-cell-specific Vegfr-2 knockout mice provided in vivo evidence for a direct chemo-attractive effect of VEGF on neurons via VEGFR-2 signaling (Ruiz de Almodovar et al. 2010).

Ablation of Vegfr-2 in neuronal cells using nestin promoter-driven CRE-mediated recombination has not produced detectable anomalies of neurogenesis (Haigh et al. 2003), indicating that although VEGFR-2 can mediate growth of neuronal progenitor cells, it is not critical for neurogenesis. Adult neurogenesis in the SVZ is also unaffected in CaMKII-CRE, loxVegf- $a$ mice, which bear a conditional ablation of VEGF-A expression in neurons, suggesting that the main source of VEGF-A in the brain is not provided by the neurons (Licht et al. 2010). In addition, several reports indicate that other members of the VEGF/VEGFR family expressed by neural cells promote neurogenesis and could functionally compensate the absence of VEGF-A. VEGF-B, a VEGFR-2 ligand, has a trophic role in adult neurogenesis, as shown by impaired neurogenesis of Vegf- $b$ $\mathrm{KO}$ mice and the neurogenesis-promoting effect of VEGF-B, which is able to restore neurogenesis in Vegf-b-KO (Sun et al. 2006). The lymphangiogenic factor VEGF-C is also expressed in the embryonic (LeBras et al. 2006) and adult brain (Shin et al. 2008; Calvo et al. 2011) in rodents. Vegf-c deletion in the mouse, as well as VEGF-C knockdown in Xenopus tadpoles, inhibited proliferation of neural progenitor cells in the forebrain, without defects of the brain vasculature, indicating that VEGF-C is a trophic factor for subsets of neural progenitor cells in the vertebrate embryonic brain (LeBras et al. 2006). The high-affinity VEGF-C receptor VEGFR-3 is also expressed by embryonic and adult neural cells (Choi et al. 2010; Calvo et al. 2011). Using transgenic VEGFR-3 mice expressing a YFP reporter or conditional deletions of VEGFR-3 in neural cells, we have shown that, in the adult SVZ, VEGF-C/VEGFR-3 signaling acted in niche astrocytes and NSCs to stimulate neurogenesis (Calvo et al. 2011). Therefore, VEGF/VEGFR family members provide complementary signals to the different cellular populations in the neurovascular niche, VEGF-C/VEGFR-3 signaling supporting resident astrocytes and stimulating NSC divisions, whereas VEGF-A/VEGFR-2 signaling maintains the niche vasculature and promotes amplification and migration of neuronal progenitors (Fig. 3).

\section{VEGF AS A GUIDANCE CUE FOR GROWING AXONS}

VEGF promotes the extension of axons of various types of neurons in vitro (Silverman et al. 1999; Sondell et al. 1999, 2000). In vivo, VEGF has been recently implicated in axon guidance in the visual system (Erskine et al. 2011). Axons from retinal ganglion cells (RGCs) relay visual information from the retina to the visual cortex, via the optic nerve and the optic chiasm of the diencephalon. At the chiasm, individual axons either remain on the ipsilateral side of the chiasm or cross the midline to reach their targets in the contralateral visual cortex. Coordinated projection to both hemispheres ensures binocular vision in species with frontally located eyes. In mice, which have laterally located eyes and limited binocular vision, most axons cross to the contralateral side. VEGF-A is expressed in the optic chiasm at the period of development when RGC axons cross it (Erskine et al. 2011). Loss of VEGF164 and its NRP-1 receptor leads to increased ipsilateral projections at the expense of contralateral projections. VEGF164 promotes growth and attracts and properly guides NRP-1-expressing RGC axons at the optic chiasm, independently of any effect on blood vessels. Therefore, RGC axons crossing the midline use VEGF as a guidance cue and NRP-1 as a receptor for VEGF164. Surprisingly, VEGFR-2 was not implicated in this axonal guidance of RGC axons. VEGF-A is also acting on commissural axons at the floor plate of the spinal cord, but through VEGFR-2 signaling (Ruiz de Almodovar 2011). VEGFR-2 has also been implicated in unexpected nonVEGF-mediated axonal guidance of a subset of hippocampal neurons (Bellon et al. 2010). The subicular neurons project VEGFR-2-expressing axons in the postcommissural fornix 
tract, and conditional deletion of Vegfr2 in neural cells leads to a developmental delay and a reduction in the size of this tract. Intriguingly, VEGF ligands have little or no effect on growth of these axons in vitro, and VEGFR-2 is thought to function as part of a PlexinD1/NRP-1 receptor complex for Sema 3E in the development of the postcommissural fornix pathway (Chauvet et al. 2007).

\section{VEGF-A IN THE CONTROL OF NEURAL PLASTICITY}

Probably the most unexpected and also most fascinating effect of VEGF in the mammalian brain is the control of plasticity. The Keshet laboratory used a conditional transgenic system expressing soluble VEGFR-1 (VEGFR-1-Ig) to suppress VEGF signaling in the mouse adult brain within the RMS and the OB (Licht et al. 2010) or in the hippocampus (Licht et al. 2011). In the OB, VEGF is constitutively expressed by distinct types of resident neurons, and VEGF sequestration by VEGFR1-Ig impairs dendrite development in newborn neurons, as indicated by the reduced dendritic spine density of granule cells and the shorter and less branched dendrites of periglomerular neurons. The effect of VEGF on dendritogenesis is independent from its role in vascular maintenance, because only dendritogenesis, but not vasculature and perfusion of the SVZ, RMS, and OB, was modified by VEGF blockade after birth. The requirement for VEGF is specific to newly born $\mathrm{OB}$ neurons, because dendrites of already established neurons are not damaged by VEGF sequestration (Licht et al. 2010). In the hippocampus, VEGF overexpression promoted angiogenesis, neurogenesis, and memory and increased long-term potentiation (LTP) responses, and thus plasticity, in the dentate gyrus in vivo. Switching off ectopic VEGF production resulted in a return to a normal LTP. Strikingly, LTP was completely abrogated by VEGF blockade, without reduction of vascularization or neurogenesis. Therefore, VEGF affects cognition processes by reversibly modulating LTP responses in hippocampal circuits. A decreased expression of VEGF-A correlates with an increased expression of mitogen-activated protein kinase phosphatase-1 (MKP-1) in hippocampal subfields of patients with major depressive disease (Duric et al. 2010), indicating that activation of VEGF signaling might improve this condition by increasing neuronal plasticity.

\section{CONCLUDING REMARKS}

Defining the signaling pathways that promote the formation and differentiation of the brain vasculature has important clinical ramifications because diseases of the CNS vasculature are a leading cause of death in the United States. First, understanding the mechanisms governing CNS vascularization may lead to strategies increasing brain vascularization in ischemia, caused, for example, by thrombotic stroke. In such conditions, improving vascularization is beneficial for the regeneration of the CNS after the event, with important therapeutic implications. However, the newly formed vasculature must display strict permeability control and vascular stability to avoid hemorrhages. Second, new insights into the mechanisms leading to $\mathrm{BBB}$ formation might allow the development of tools to reversibly "open" the BBB, which would improve drug delivery to the brain. Highmolecular-weight molecules such as antibodies, peptides, and drugs that are active against neurological disorders, including neurodegenerative disease and cerebral tumors, are limited in their therapeutic action by their poor ability to cross the BBB. Third, in addition to their role in angiogenesis, VEGF family members emerge as potent regulators of neurogenesis and neural plasticity and represent, together with their receptors, therapeutic targets for neural tissue repair and neurodegenerative disease (Ferrara et al. 2003; Storkebaum and Carmeliet 2004; Ruiz de Almodovar et al. 2009). Finally, some of the most aggressive brain tumors such as glioblastoma are highly angiogenic, as already noted by Folkman and colleagues (Klagsbrun et al. 1976). The existence of a cancer stem cell-vascular niche complex, where ECs propagate brain tumor survival in vivo, has been proposed (Calabrese et al. 2007), and further research into tumor niche- 
vascular interactions may provide novel strategies to block brain tumor growth.

\section{ACKNOWLEDGMENTS}

We apologize for not being able to cite all relevant work because of space restrictions. We wish to thank Luc Pardanaud, Claudia Prahst, and Clara Alfaro-Cervello for illustrations. This review is dedicated to the memory of Judah Folkman. It was a privilege to have known Judah, who was a wonderful personality and a visionary scientist who anticipated many of the findings reviewed here years before their actual publication.

\section{REFERENCES}

Anderson KD, Pan L, Yang XM, Hughes VC, Walls JR, Dominguez MG, Simmons MV, Burfeind P, Xue Y, Wei Y, et al. 2011. Angiogenic sprouting into neural tissue requires Gpr124, an orphan $\mathrm{G}$ protein-coupled receptor. Proc Natl Acad Sci 108: 2807-2812.

Andreu-Agulló C, Morante-Redolat JM, Delgado AC, Fariñas I. 2009. Vascular niche factor PEDF modulates Notch-dependent stemness in the adult subependymal zone. Nat Neurosci 12: 1514-1523.

Armulik A, Genové G, Mäe M, Nisancioglu MH, Wallgard E, Niaudet C, He L, Norlin J, Lindblom P, Strittmatter K, et al. 2010. Pericytes regulate the blood-brain barrier. Nature 468: 557-561.

Bautch VL, James JM. 2009. Neurovascular development: The beginning of a beautiful friendship. Cell Adh Migr 3: 199-204.

Bellon A, Luchino J, Haigh K, Rougon G, Haigh J, Chauvet S, Mann F. 2010. VEGFR2 (KDR/Flk1) signaling mediates axon growth in response to semaphorin $3 \mathrm{E}$ in the developing brain. Neuron 66: 205-219.

Borrell V, Marín O. 2006. Meninges control tangential migration of hem-derived Cajal-Retzius cells via CXCL12/CXCR4 signaling. Nat Neurosci 9: 1284-1293.

Bovetti S, Hsieh YC, Bovolin P, Perroteau I, Kazunori T, Puche AC. 2007. Blood vessels form a scaffold for neuroblast migration in the adult olfactory bulb. J Neurosci 27: 5976-5980.

Breier G, Albrecht U, Sterrer S, Risau W. 1992. Expression of vascular endothelial growth factor during embryonic angiogenesis and endothelial cell differentiation. Development 114: 521-532.

Calabrese C, Poppleton H, Kocak M, Hogg TL, Fuller C, Hamner B, Oh EY, Gaber MW, Finklestein D, Allen M, et al. 2007. A perivascular niche for brain tumor stem cells. Cancer Cell 21: 3332-3341.

Calvo CF, Fontaine RH, Soueid J, Tammela T, Makinen T, Alfaro-Cervello C, Bonnaud F, Miguez A, Benhaim L, $\mathrm{Xu} \mathrm{Y}$, et al. 2011. Vascular endothelial growth factor receptor 3 directly regulates murine neurogenesis. Genes Dev 25: 831-844.

Chauvet S, Cohen S, Yoshida Y, Fekrane L, Livet J, Gayet O, Segu L, Buhot MC, Jessell TM, Henderson CE, et al. 2007. Gating of Sema3E/PlexinD1 signaling by neuropilin-1 switches axonal repulsion to attraction during brain development. Neuron 56: 807-822.

Choi JS, Shin YJ, Lee JY, Yun H, Cha JH, Choi JY, Chun MH, Lee MY. 2010. Expression of vascular endothelial growth factor receptor-3 mRNA in the rat developing forebrain and retina. J Comp Neurol 518: 1064-1081.

Damon DH, Teriele JA, Marko SB. 2007. Vascular-derived artemin: A determinant of vascular sympathetic innervation? Am J Physiol Heart Circ Physiol 293: H266-H273.

Daneman R, Agalliu D, Zhou L, Kuhnert F, Kuo CJ, Barres BA. 2009. Wnt $/ \beta$-catenin signaling is required for CNS, but not non-CNS, angiogenesis. Proc Natl Acad Sci 106: 641-646.

Daneman R, Zhou L, Kebede AA, Barres BA. 2010. Pericytes are required for blood-brain barrier integrity during embryogenesis. Nature 468: 562-566.

Dejana E. 2010. The role of Wnt signaling in physiological and pathological angiogenesis. Circ Res 107: 943-952.

del Toro R, Prahst C, Mathivet T, Siegfried G, Kaminker JS, Larrivee B, Breant C, Duarte A, Takakura N, Fukamizu A, et al. 2010. Identification and functional analysis of endothelial tip cell-enriched genes. Blood 116: 4025-4033.

Doetsch F. 2003. A niche for adult neural stem cells. Curr Opin Genet Dev 13: 543-550.

Dorrell M, Uusitalo-Jarvinen H, Aguilar E, Friedlander M. 2007. Ocular neovascularization: Basic mechanisms and therapeutic advances. Surv Ophthalmol 52: S3-S19.

Duric V, Banasr M, Licznerski P, Schmidt HD, Stockmeier CA, Simen AA, Newton SS, Duman RSA. 2010. A negative regulator of MAP kinase causes depressive behavior. Nat Med 16: 1328-1332.

Engelhardt B. 2003. Development of the blood-brain barrier. Cell Tissue Res 314: 119-129.

Erskine L, Reijntjes S, Pratt T, Denti L, Schwarz Q, Vieira JM, Alakakone B, Shewan D, Ruhrberg C. 2011. VEGF signalling through neuropilin 1 guides commissural axon crossing at the optic chiasm. Neuron 70: 951-965.

Etchevers HC, Vincent C, Le Douarin NM, Couly GF. 2001. The cephalic neural crest provides pericytes and smooth muscle cells to all blood vessels of the face and forebrain. Development 128: 1059-1068.

Feeney JF, Watterson RL. 1946. The development of the vascular pattern within the walls of the central nervous system of the chick embryo. J Morphol 78: 231-303.

Ferrara N. 2010. Vascular endothelial growth factor and age-related macular degeneration: From basic science to therapy. Nat Med 16: 1107-1111.

Ferrara N, Gerber HP, LeCouter J. 2003. The biology of VEGF and its receptors. Nat Med 9: 669-676.

Franco CA, Liebner S, Gerhardt H. 2009. Vascular morphogenesis: AWnt for every vessel? Curr Opin Genet Dev 19: $476-483$.

Garcia CM, Darland DC, Massingham LJ, D'Amore PA. 2004. Endothelial cell-astrocyte interactions and TGF $\beta$ are required for induction of blood-neural barrier properties. Brain Res Dev Brain Res 152: 25-38. 
Gerhardt H, Golding M, Fruttiger M, Ruhrberg C, Lundkvist A, Abramsson A, Jeltsch M, Mitchell C, Alitalo K, Shima D, et al. 2003. VEGF guides angiogenic sprouting utilizing endothelial tip cell filopodia. J Cell Biol 161: 1163-1177.

Greenberg DA, Jin K. 2005. From angiogenesis to neuropathology. Nature 438: 954-959.

Gu C, Rodriguez ER, Reimert DV, Shu T, Fritzsch B, Richards LJ, Kolodkin AL, Ginty DD. 2003. Neuropilin-1 conveys semaphorin and VEGF signaling during neural and cardiovascular development. Dev Cell 5: 45-57.

Haigh JJ, Morelli PI, Gerhardt H, Haigh K, Tsien J, Damert A, Miquerol L, Muhlner U, Klein R, Ferrara N, et al. 2003. Cortical and retinal defects caused by dosage-dependent reductions in VEGF-A paracrine signaling. Dev Biol 262: 225-241.

Hartog TE, Dittrich F, Pieneman AW, Jansen RF, FranklVilches C, Lessmann V, Lilliehook C, Goldman SA, Gahr M. 2009. Brain-derived neurotrophic factor signaling in the $\mathrm{HVC}$ is required for testosterone-induced song of female canaries. J Neurosci 29: 15511-15519.

Hashimoto T, Zhang XM, Chen BY, Yang XJ. 2006. VEGF activates divergent intracellular signaling components to regulate retinal progenitor cell proliferation and neuronal differentiation. Development 133: 2201-2210.

Hawkins BT, Davis TP. 2005. The blood-brain barrier/neurovascular unit in health and disease. Pharmacol Rev 57: 173-185.

Hellstrom M, Phng LK, Hofmann JJ, Wallgard E, Coultas L, Lindblom P, Alva J, Nilsson AK, Karlsson L, Gaiano N, et al. 2007. Dll4 signalling through Notch1 regulates formation of tip cells during angiogenesis. Nature $\mathbf{4 4 5}$ $776-780$.

Iadecola C. 2004. Neurovascular regulation in the normal brain and in Alzheimer's disease. Nat Rev Neurosci 5 347-360.

Jin KL, Mao XO, Greenberg DA. 2000. Vascular endothelial growth factor: Direct neuroprotective effect in in vitro ischemia. Proc Natl Acad Sci 97: 10242-10247.

Junge HJ, Yang S, Burton JB, Paes K, Shu X, French DM, Costa M, Rice DS, Ye W. 2009. TSPAN12 regulates retinal vascular development by promoting Norrin- but not Wnt-induced FZD4/ $\beta$-catenin signaling. Cell 139: 299-311.

Klagsbrun M, Eichmann A. 2005. A role for axon guidance receptors and ligands in blood vessel development and tumor angiogenesis. Cytokine Growth Factor Rev 16: 535-548.

Klagsbrun M, Knighton D, Folkman J. 1976. Tumor angiogenesis activity in cells grown in tissue culture. Cancer Res 36: $110-114$.

Kokovay E, Goderie S, Wang Y, Lotz S, Lin G, Sun Y, Roysam B, Shen Q, Temple S. 2010. Adult SVZ lineage cells home to and leave the vascular niche via differential responses to SDF1/CXCR4 signaling. Cell Stem Cell 7: 163-173.

Kriegstein A, Alvarez-Buylla A. 2009. The glial nature of embryonic and adult neural stem cells. Annu Rev Neurosci 32: $149-184$.

Kuhn HG, Dickinson-Anson H, Gage FH. 1996. Neurogenesis in the dentate gyrus of the adult rat: Age related decrease of neuronal progenitor proliferation. J Neurosci 16: 2027-2033.

Kuhnert F, Mancuso MR, Shamloo A, Wang HT, Choksi V, Florek M, Su H, Fruttiger M, Young WL, Heilshorn SC, et al. 2010. Essential regulation of CNS angiogenesis by the orphan G protein-coupled receptor GPR124. Science 330: 985-989.

Larrivée B, Freitas C, Suchting S, Brunet I, Eichmann A. 2009. Guidance of vascular development: Lessons from the nervous system. Circ Res 104: 428-411.

Le Bras B, Barallobre MJ, Homman-Ludiye J, Ny A, Wyns S, Tammela T, Haiko P, Karkkainen MJ, Yuan L, Muriel MP, et al. 2006. VEGF-C is a trophic factor for neural progenitors in the vertebrate embryonic brain. Nat Neurosci 9: 340-348.

Lee HS, Han J, Bai HJ, Kim KW. 2009. Brain angiogenesis in developmental and pathological processes: Regulation, molecular and cellular communication at the neurovascular interface. FEBS J 276: 4622-4635.

Licht T, Eavri R, Goshen I, Shlomai Y, Mizrahi A, Keshet E. 2010. VEGF is required for dendritogenesis of newly born olfactory bulb interneurons. Development 137: 261-271.

Licht T, Goshen I, Avital A, Kreisel T, Zubedat S, Eavri R, Segal M, Yirmiya R, Keshet E. 2011. Reversible modulations of neuronal plasticity by VEGF. Proc Natl Acad Sci 108: $5081-5086$.

Liebner S, Corada M, Bangsow T, Babbage J, Taddei A, Czupalla CJ, Reis M, Felici A, Wolburg H, Fruttiger M, et al. 2008. Wnt/ $\beta$-catenin signaling controls development of the blood-brain barrier. J Cell Biol 183: 409-417.

Lindahl P, Johansson BR, Leveen P, Betsholtz C. 1997. Pericyte loss and microaneurysm formation in PDGFB-deficient mice. Science 277: 242-245.

Lindblom P, Gerhardt H, Liebner S, Abramsson A, Enge M, Hellstrom M, Backstrom G, Fredriksson S, Landegren U, Nystrom HC, et al. 2003. Endothelial PDGF-B retention is required for proper investment of pericytes in the microvessel wall. Genes Dev 17: 1835-1840.

Louissaint A Jr, Rao S, Leventhal C, Goldman SA. 2002. Coordinated interaction of neurogenesis and angiogenesis in the adult songbird brain. Neuron 34: 945-960.

Loulier K, Lathia JD, Marthiens V, Relucio J, Mughal MR, Tang SC, Coksaygan T, Hall PE, Chigurupati S, Patton B, et al. 2009. $\beta 1$ integrin maintains integrity of the embryonic neocortical stem cell niche. PLoS Biol 8: e1000176. doi: 10.1371/journal.pbio.1000176.

Makita T, Sucov HM, Gariepy CE, Yanagisawa M, Ginty DD. 2008. Endothelins are vascular-derived axonal guidance cues for developing sympathetic neurons. Nature 452: 759-763.

McCarty JH, Lacy-Hulbert A, Charest A, Bronson RT, Crowley D, Housman D, Savill J, Roes J, Hynes RO. 2005. Selective ablation of $\alpha \mathrm{v}$ integrins in the central nervous system leads to cerebral hemorrhage, seizures, axonal degeneration and premature death. Development 132: $165-176$.

Merkle FT, Tramontin AD, García-Verdugo JM, AlvarezBuylla A. 2004. Radial glia give rise to adult neural stem cells in the subventricular zone. Proc Natl Acad Sci 101: $17528-17532$. 
Mobley AK, Tchaicha JH, Shin J, Hossain MG, McCarty JH 2009. $\beta 8$ integrin regulates neurogenesis and neurovascular homeostasis in the adult brain. J Cell Sci 122: $1842-1851$.

Ogunshola OO, Antic A, Donoghue MJ, Fan SY, Kim H, Stewart WB, Madri JA, Ment LR. 2002. Paracrine and autocrine functions of neuronal vascular endothelial growth factor (VEGF) in the central nervous system. J Biol Chem 277: 11410-11415.

Palmer TD, Willhoite AR, Gage FH. 2000. Vascular niche for adult hippocampal neurogenesis. J Comp Neurol 425: 479-494.

Phng LK, Gerhardt H. 2009. Angiogenesis: A team effort coordinated by Notch. Dev Cell 16: 196-208.

Popovici C, Isnardon D, Birnbaum D, Roubin R. 2002. Caenorhabditis elegans receptors related to mammalian vascular endothelial growth factor receptors are expressed in neural cells. Neurosci Lett 329: 116-120.

Procko C, Lu Y, Shaham S. 2011. Glia delimits shape changes of sensory neuron receptive endings in C. elegans. Development 138: 1371-1381.

Proctor JM, Zang K, Wang D, Wang R, Reichardt LF. 2005. Vascular development of the brain requires $\beta 8$ integrin expression in the neuroepithelium. J Neurosci 25: 9940-9948.

Raab S, Beck H, Gaumann A, Yüce A, Gerber HP, Plate K, Hammes HP, Ferrara N, Breier G. 2004. Impaired brain angiogenesis and neuronal apoptosis induced by conditional homozygous inactivation of vascular endothelial growth factor. Thromb Haemost 91: 595-605.

Ramírez-Castillejo C, Sánchez-Sánchez F, Andreu-Agulló C, Ferrón SR, Aroca-Aguilar JD, Sánchez P, Mira H, Escribano J, Fariñas I. 2006. Pigment epithelium-derived factor is a niche signal for neural stem cell renewal. Nat Neurosci 3: 331-339.

Rosenstein JM, Krum JM, Ruhrberg C. 2010. VEGF in the nervous system. Organogenesis 6: 107-114.

Rubin LL, Staddon JM. 1999. The cell biology of the bloodbrain barrier. Annu Rev Neurosci 22: 11-28.

Ruiz de Almodovar C, Lambrechts D, Mazzone M, Carmeliet P. 2009. Role and therapeutic potential of VEGF in the nervous system. Physiol Rev 89: 607-648.

Ruiz de Almodovar C, Coulon C, Salin PA, Knevels E, Chounlamountri N, Poesen K, Hermans K, Lambrechts D, Van Geyte K, Dhondt J, et al. 2010. Matrix-binding vascular endothelial growth factor (VEGF) isoforms guide granule cell migration in the cerebellum via VEGF receptor Flk1. J Neurosci 30: 15052-15066.

Ruiz de Almodovar C, Fabre PJ, Knevels E, Coulon C, Segura L, Haddick PC, Aerts L, Delattin N, Strasser G, Oh WJ, et al. 2011. VEGF mediates commissural axon chemoattraction through its receptor Flk1. Neuron 70: 966-978.

Shen Q, Goderie SK, Jin L, Karanth N, Sun Y, Abramova N, Vincent P, Pumiglia K, Temple S. 2004. Endothelial cells stimulate self-renewal and expand neurogenesis of neural stem cells. Science 304: 1338-1340.

Shen Q, Wang Y, Kokovay E, Lin G, Chuang SM, Goderie SK, Roysam B, Temple S. 2008. Adult SVZ stem cells lie in a vascular niche: A quantitative analysis of niche cell-cell interactions. Cell Stem Cell 3: 289-300.
Sheppard D. 2004. Roles of $\alpha \mathrm{v}$ integrins in vascular biology and pulmonary pathology. Curr Opin Cell Biol 5: 552-557.

Shin YJ, Choi JS, Lee JY, Choi JY, Cha JH, Chun MH, Lee MY. 2008. Differential regulation of vascular endothelial growth factor-C and its receptor in the rat hippocampus following transient forebrain ischemia. Acta Neuropathol 116: 517-527.

Shingo T, Gregg C, Enwere E, Fujikawa H, Hassam R, Geary C, Cross JC, Weiss S. 2003. Pregnancy-stimulated neurogenesis in the adult female forebrain mediated by prolactin. Science 299: 117-120.

Silverman WF, Krum JM, Mani N, Rosenstein JM. 1999. Vascular, glial and neuronal effects of vascular endothelial growth factor in mesencephalic explant cultures. $\mathrm{Neu}$ roscience 90: 1529-1541.

Snapyan M, Lemasson M, Brill MS, Blais M, Massouh M, Ninkovic J, Gravel C, Berthod F, Götz M, Barker PA, et al. 2009. Vasculature guides migrating neuronal precursors in the adult mammalian forebrain via brainderived neurotrophic factor signaling. J Neurosci 29: 4172-4188.

Sondell M, Lundborg G, Kanje M. 1999. Vascular endothelial growth factor has neurotrophic activity and stimulates axonal outgrowth, enhancing cell survival and Schwann cell proliferation in the peripheral nervous system. Neuroscience 19: 5731-5740.

Sondell M, Sundler F, Kanje M. 2000. Vascular endothelial growth factor is a neurotrophic factor which stimulates axonal outgrowth through the flk1 receptor. Eur J Neurosci 12: $4243-4254$.

Stenman JM, Rajagopal J, Carroll TJ, Ishibashi M, McMahon J, McMahon AP. 2008. Canonical Wnt signaling regulates organ-specific assembly and differentiation of CNS vasculature. Science 322: 1247-1250.

Storkebaum E, Carmeliet P. 2004. VEGF: A critical player in neurodegeneration. J Clin Invest 113: 14-18.

Strasser GA, Kaminker JS, Tessier-Lavigne M. 2010. Microarray analysis of retinal endothelial tip cells identifies CXCR4 as a mediator of tip cell morphology and branching. Blood 115: 5102-5110.

Suchting S, Freitas C, le Noble F, Benedito R, Breant C, Duarte A, Eichmann A. 2007. The Notch ligand Deltalike 4 negatively regulates endothelial tip cell formation and vessel branching. Proc Natl Acad Sci 104: 3225-3230.

Sun Y, Jin K, Childs JT, Xie L, Mao XO, Greenberg DA. 2006. Vascular endothelial growth factor-B (VEGFB) stimulates neurogenesis: Evidence from knockout mice and growth factor administration. Dev Biol 289: 329-335.

Takata F, Dohgu S, Yamauchi A, Sumi N, Nakagawa S, Naito M, Tsuruo T, Shuto H, Kataoka Y. 2007. Inhibition of transforming growth factor- $\beta$ production in brain pericytes contributes to cyclosporin A-induced dysfunction of the blood-brain barrier. Cell Mol Neurobiol 27: 317-328.

Tam SJ, Watts RJ. 2010. Connecting vascular and nervous system development: Angiogenesis and the blood-brain barrier. Annu Rev Neurosci 33: 379-408.

Tammela T, Zarkada G, Wallgard E, Murtomaki A, Suchting S, Wirzenius M, Waltari M, Hellstrom M, Schomber T, Peltonen R, et al. 2008. Blocking VEGFR-3 suppresses 
angiogenic sprouting and vascular network formation. Nature 454: 656-660.

Tavazoie M, Van der Veken L, Silva-Vargas V, Louissaint M, Colonna L, Zaidi B, Garcia-Verdugo JM, Doetsch F. 2008. A specialized vascular niche for adult neural stem cells. Cell Stem Cell 3: 279-288.

Tessier-Lavigne M, Goodman CS. 1996. The molecular biology of axon guidance. Science 274: 1123-1133.

Tombran-Tink J, Barnstable CJ. 2003. PEDF: A multifaceted neurotrophic factor. Nat Rev Neurosci 8: 628-636.

Warden SM, Andreoli CM, Mukai S. 2007. The Wnt signaling pathway in familial exudative vitreoretinopathy and Norrie disease. Semin Ophthalmol 22: 211-217.

Wittko IM, Schänzer A, Kuzmichev A, Schneider FT, Shibuya M, Raab S, Plate KH. 2009. VEGFR-1 regulates adult olfactory bulb neurogenesis and migration of neural progenitors in the rostral migratory stream in vivo. J Neurosci 29: 8704-8714.

Yang X, Cepko CL. 1996. Flk-1, a receptor for vascular endothelial growth factor (VEGF), is expressed by retinal progenitor cells. J Neurosci 16: 6089-6099.

Ye X, Wang Y, Cahill H, Yu M, Badea TC, Smallwood PM, Peachey NS, Nathans J. 2009. Norrin, frizzled-4, and Lrp5 signaling in endothelial cells controls a genetic program for retinal vascularization. Cell 139: 285-298.

Yourey PA, Gohari S, Su JL, Alderson RF. 2000. Vascular endothelial cell growth factors promote the in vitro development of rat photoreceptor cells. J Neurosci 20: 6781-6788. 


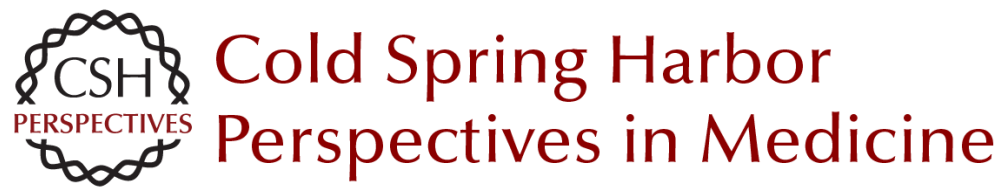

\title{
Molecular Parallels between Neural and Vascular Development
}

\author{
Anne Eichmann and Jean-Léon Thomas
}

Cold Spring Harb Perspect Med 2013; doi: 10.1101/cshperspect.a006551 originally published online September 28, 2012

\section{Subject Collection Angiogenesis}

Extracellular Matrix Regulation of Vascular Morphogenesis, Maturation, and Stabilization George E. Davis and Scott S. Kemp

Endothelial Cell-Pericyte Interactions in the Pathogenesis of Cerebral Cavernous Malformations (CCMs) Wang Min and Jenny Huanjiao Zhou

Lymphatic Clearance and Pump Function Jerome W. Breslin

Platelets and (Lymph)angiogenesis Harvey G. Roweth and Elisabeth M. Battinelli

Modeling Brain Vasculature Immune Interactions In Vitro Ruth Lyck, Hideaki Nishihara, Sidar Aydin, et al.

Human Endothelial Colony-Forming Cells Juan M. Melero-Martin

\section{The Beauty and Complexity of Blood Vessel} Patterning

Victoria L. Bautch and Yoh-suke Mukouyama

Endothelialitis, Microischemia, and

Intussusceptive Angiogenesis in COVID-19 Steven J. Mentzer, Maximilian Ackermann and Danny Jonigk
Regulation of the Blood-Brain Barrier in Health and Disease Cara C. Rada, Kanako Yuki, Jie Ding, et al.

Targeting Angiogenesis via Resolution of Inflammation

Abigail G. Kelly and Dipak Panigrahy

Notch Signaling in the Vasculature: Angiogenesis and Angiocrine Functions

Sana S. Hasan and Andreas Fischer

Signal Transduction and Gene Regulation in the Endothelium

Michel V. Levesque and Timothy Hla

Buttons and Zippers: Endothelial Junctions in

Lymphatic Vessels

Peter Baluk and Donald M. McDonald

Endothelial Cell Fate Determination: A Top Notch Job in Vascular Decision-Making

L.A. Naiche, Stephanie R. Villa and Jan K. Kitajewski

Leukocyte Trafficking in Lymphatic Vessels Aline Bauer, Hazal Tatliadim and Cornelia Halin

Lymphatic Tissue and Organ Engineering for In Vitro Modeling and In Vivo Regeneration Anna M. Kolarzyk, Gigi Wong and Esak Lee

For additional articles in this collection, see http://perspectivesinmedicine.cshlp.org/cgi/collection/ 